\title{
Mass transfer of non-polar heavy hydrocarbons in aqueous phase
}

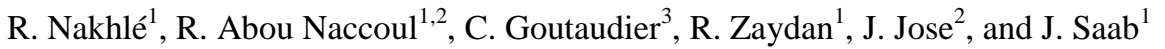 \\ ${ }^{1}$ Université Saint Esprit de Kaslik, Faculty of Sciences, work group « Thermodynamic, Phases Equilibrium, and \\ Advanced Analysis», Dept. Chemistry and Life Sciences, B.P 446, Jounieh, Lebanon \\ ${ }^{2}$ Université Claude Bernard Lyon 1, UMR 5180 Analytical Sciences, work gourp «Thermodynamique et Analyse en \\ ligne» Bât J.Raulin, 43 boulevard du 11 novembre 1918, 69622 Villeurbanne Cedex, France \\ ${ }^{3}$ Université Claude Bernard Lyon 1, Laboratoire Multimatériaux et Interfaces, UMR 5615 CNRS, bât Chevreul, 43 bd 11 \\ novembre 1918, 69622 Villeurbanne Cedex France
}

Low aqueous solubilities are data of great importance in both industrial and environmental fields. As for the low aqueous solubility, we present the experimental apparatus along with the optimizations and adjustments (mechanical and analytical) applied to measure the solubility of heavy polyaromtics (solubility down to $10^{-9}$ in molal). The validation of our apparatus was achieved by measuring the aqueous solubility of the Fluoranthene in a range between 298.15 and $338.15 \mathrm{~K}$. The quantification was done using GC-MS SIM with internal calibration method with benzo(a)pyrene as internal standard. Solubility of $\operatorname{dibenz}(\mathrm{a}, \mathrm{c})$ anthracene was then explored between 298 and $333 \mathrm{~K}$ with an extremely low solubility of $10^{-12}$ in molar fraction.

\section{Introduction}

Since the last decade, an increase attention is being accorded to the long-term effects of the chemical pollutants called xenobiotic (Polycyclic Aromatic Hydrocarbons PAHs, Organotins,...) on the environment and the human health. Thus, to predict the partition equilibrium of these pollutants on the interface "HumanEnvironment", it would be necessary to study their (1) physico-chemical properties (Phase: exposure or distribution of the pollutant in the various compartments "Sediment/ Air/ Water/Food/Biota") which by combination with their fate (2) make these pollutants more or less available to the human or bioavailability . The thermophysical properties to evaluate are: vapor pressure "P" (inhalation risks), aqueous solubility "S" (estimate the concentrations of the pollutant in water), Henry's constant " $\mathrm{K}_{\mathrm{H}}$ " (estimate the vaporization of an aqueous medium, air/water equilibrium), Octanol/water partition coefficient "Kow" (estimation of potential bioaccumulation in living organism) and finally the coefficient of partition water-sediment "Koc" (estimate the migration in the sediment).

In addition, water solubility data permit assess of some thermodynamic properties which otherwise are very difficult to obtain through direct calorimetric or volumetric determination due to the very low concentration of the solute. Water solubility is an important physico-chemical parameter that affects the fate and the transport of organic chemicals in the environment and potential distribution throughout the hydrologic system causing the exposure to this xenobiotic compound $[4,7,11]$.

However, the distribution between phases for many pollutants on a trace scale or ultra-trace (very hydrophobic) remains unknown and difficult to be experimentally determined. In this paper, we present a dynamic saturation procedure the experimental apparatus along with the optimizations and adjustments (mechanical and analytical) applied to measure the solubility of low soluble molecules. After experimental optimization of the different compartment, validation process is achieved by mean of PAH, Fluoranthene. Study of temperature dependence solubility of 1,2,3,4dibenzoanthracene (DBA [a,c]) was determined in the range from $298 \mathrm{~K}$ to $333 \mathrm{~K}$ [1-3].

\section{Aqueous solubility determination}

\subsection{Procedure and operation}

The dynamic saturation apparatus is shown in figure 1 . The apparatus is mainly divided into three parts. First is the generator, where solvents are pumped. Second is the saturation where fluid is saturated. Third is the analysis part where final composition is determined $[1,14]$. 


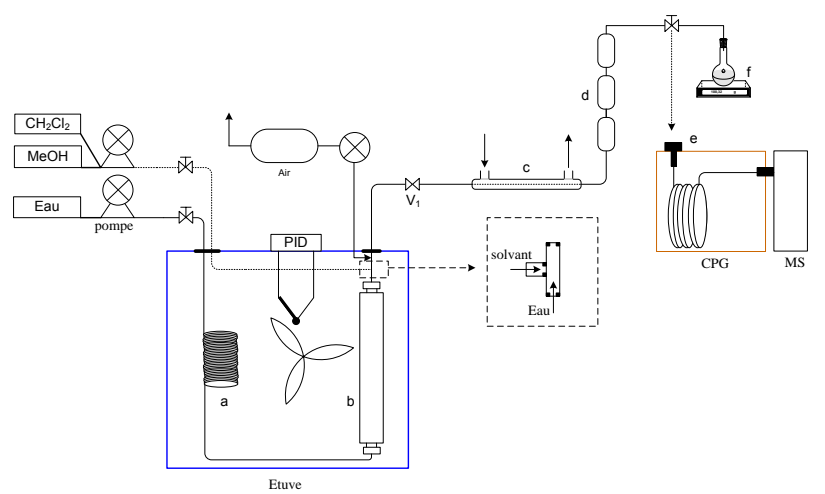

Figure 1. Dynamic saturation apparatus for low aqueous solubility determination

(a): Preheating coil; (b): Saturation Cell; (c): Refrigerant; (d): Extraction Column; (e): Offline GC-MS Analysis; (f): balance.

The solvent is delivered by high pressure low stream pump with high accuracy. The pump is equipped with a double entry in order to deliver aqueous and organic solvents. The aqueous solution delivered by the pump, enters the preheating coil where it acquires the consign temperature. The preheating coil and the saturation cell are kept in a chromatographic oven where temperature varies within $\pm 0.05^{\circ} \mathrm{C}$ by means of a PID controller. The used oven can insure accurate temperature from $273.15 \mathrm{~K}$ to $673.15 \mathrm{~K}$. Water exiting the preheating coil get to the cell that contains a stationary phase (GazChrom R 60/80 Mesh) pre-impregnated by the studied compound. The cell is equipped by sintered stainless steel of low porosity in order to prevent the transport of the compound. The sintered materials are chosen with precaution, a very low porosity causes the raise of the pressure in the generator column, and in contrast a high porosity will not prevent the micelle from passing though leading to an error by excess in the final result.

Exiting the generator column, the primary circuit (filled line) passes though the refrigerator. The latter is used in order to minimize the solute affinity to water, in order to make the trapping system more efficient. Then, the solute is trapped subsequently in the inversed phase column and the solute free water is recuperated and weighed. Water's mass is used in solubility determination.

The elution is done by methanol or dichloromethane (depending on the compound affinity). The solvent passes through the $\mathrm{T}$ switch and directly to the inversed phase column by means of the dashed circuit. Finally, the quantification is performed using a GC-MS and a split/splitless injector with a $30 \mathrm{~m}$ capillary column ( $\mathrm{AT}^{\mathrm{TM}}-5,0.25 \mathrm{~mm}$ i.d., $0.25 \mu \mathrm{m}$ film thickness).

\subsection{Validation}

Although the experimental procedure was validated in previous publication [14], the solubility study of PAH and the modification over the experimental procedure lead us to new validation process using a polyaromatic molecule. Thus, fluoranthene $\left(\mathrm{C}_{16} \mathrm{H}_{10}\right)$ was chosen, it presents 3 aromatic rings and an estimated solubility of $3 \mathrm{E}-8$ at $298.15 \mathrm{~K}$. Solubility of fluoranthene was studied in pure water in a temperature range between $298.15 \mathrm{~K}$ and $338.15 \mathrm{~K}$. The quantification was done by internal standard calibration method benzo(a)pyrene used as internal standard) using gas chromatography coupled to mass spectrometer. Each measurement was repeated three times with relative standard deviation not exceeding the 3 $\%$ overall the temperatures. The dynamic saturation procedure was changed in order to adapt it to this low level of solubility.

Solubility is reported in mole fraction (table 1). The latter is calculated as follows (equation 1):

$$
X^{\text {sol }}=\frac{n_{\text {analyte }}}{n_{\text {water }}+n_{\text {analyte }}}
$$

with $\mathrm{X}$, solubility in mole fraction and $\mathrm{n}$, mole number.

Table 1. Experimental results of aqueous solubility of Fluoranthene PAH.

\begin{tabular}{|c|c|c|c|}
\hline $\begin{array}{c}\text { Temperature } \\
(\mathrm{K})\end{array}$ & $\begin{array}{c}\text { Solubility } \\
\left(X .10^{8}\right)\end{array}$ & $\begin{array}{l}\text { Mean Value } \\
\left(X .10^{8}\right)\end{array}$ & $\begin{array}{l}\text { RSD } \\
(\%)\end{array}$ \\
\hline \multirow{3}{*}{298.15} & $3.05( \pm 0.17)$ & \multirow{3}{*}{$2.97( \pm 0.16)$} & \multirow{3}{*}{2,72} \\
\hline & $2.89( \pm 0.16)$ & & \\
\hline & $2.97( \pm 0.16)$ & & \\
\hline \multirow{3}{*}{308.15} & $5.31( \pm 0.21)$ & \multirow{3}{*}{$5.19( \pm 0.21)$} & \multirow{3}{*}{2,01} \\
\hline & $5.10( \pm 0.20)$ & & \\
\hline & $5.17( \pm 0.21)$ & & \\
\hline \multirow{3}{*}{318.15} & $6.84( \pm 0.28)$ & \multirow{3}{*}{$6.71( \pm 0.28)$} & \multirow{3}{*}{2,07} \\
\hline & $6.56( \pm 0.27)$ & & \\
\hline & $6.72( \pm 0.28)$ & & \\
\hline \multirow{3}{*}{328.15} & $10.1( \pm 0.46)$ & \multirow{3}{*}{$10.3( \pm 0.47)$} & \multirow{3}{*}{2,27} \\
\hline & $10.6( \pm 0.48)$ & & \\
\hline & $10.3( \pm 0.47)$ & & \\
\hline \multirow{3}{*}{338.15} & $15.0( \pm 0.35)$ & \multirow{3}{*}{$15.1( \pm 0.45)$} & \multirow{3}{*}{1,77} \\
\hline & $15.0( \pm 0.35)$ & & \\
\hline & $15.5( \pm 0.55)$ & & \\
\hline
\end{tabular}

At each temperature three measurements were done in order to study the repeatability. In all cases the relative standard deviation (RSD) did not exceed the $3 \%$. Solubility showed a normal ascending tendency with temperature.

The figure 2 shows the relative deviation of our experimental value with literature at $298.15 \mathrm{~K}$. 


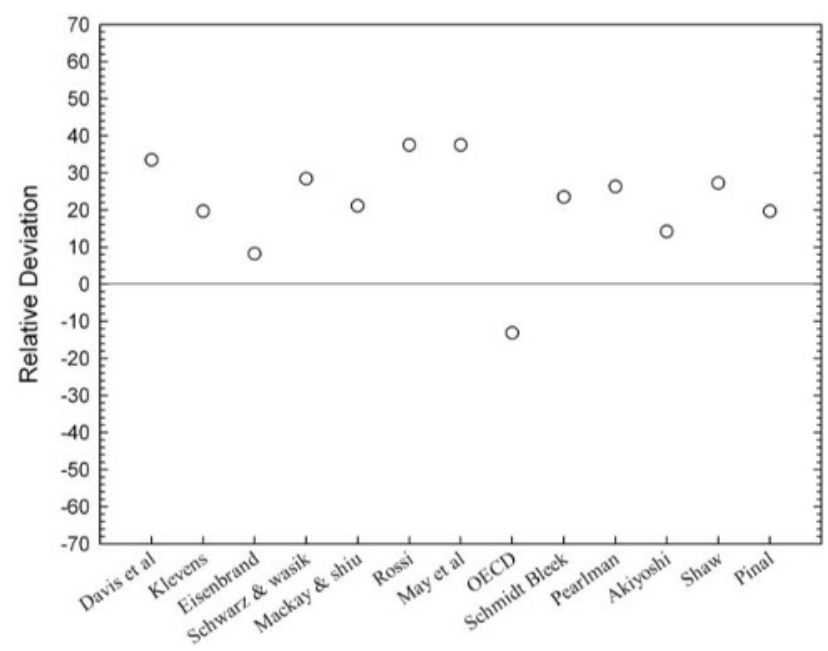

Figure 2. Relative deviation of the solubility of fluoranthene $\mathrm{PAH}$ at $298.15 \mathrm{~K}$ in comparison with the literature values.

As can be observed our work is in good agreement with the values reported by OECD (standard method) with a deviation below $8 \%$. Higher deviations are observed with Davis et al [5] and Klevens et al. [7] who used shake-flask method making the values (at this low level of solubility) inaccurate by excess due to the formation of micelles. On the other hand, deviation varied between 14 and $33 \%$ with indirect methods (RPLC and column generator method).

\subsection{Solubility of Dibenz(a,c)anthracene}

Solubility of $\operatorname{DBA}(\mathrm{a}, \mathrm{c})$ was carried out in a temperature range between $298 \mathrm{~K}$ and $333 \mathrm{~K}$. As shown in figure 3, DBA presented an increasing solubility tendency with temperature, with values between $9.10^{-12}$ and $1.10^{-10}$ in molar fraction.

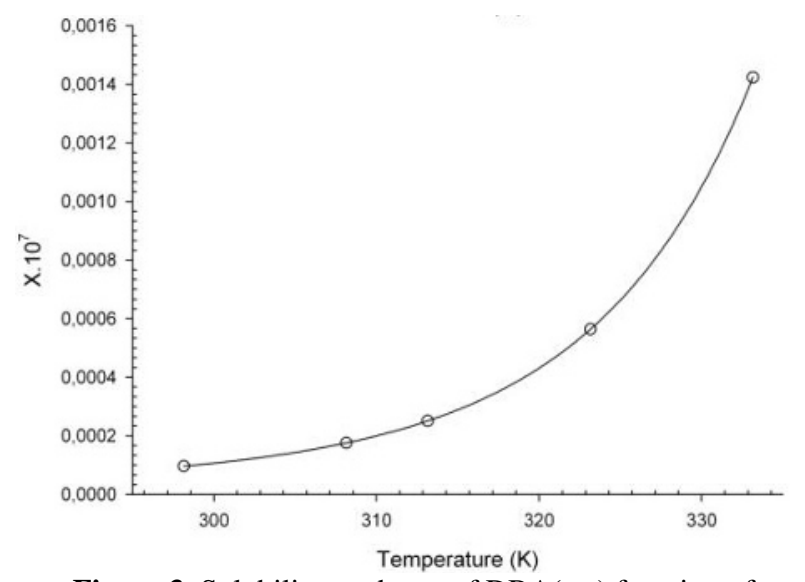

Figure 3. Solubility tendency of DBA(a,c) function of temperature.

Data were not compared to literature values, because no experimental values were found of the studied compound in the temperature range applied.

\section{Conclusion}

Dynamic saturation procedure for aqueous solubility was modified and then applied to study the physical properties of heavy compounds. The validation of the apparatus was done by means of fluoranthene. This study will be followed by a research over a wide range of polyaroamtic compounds of high importance in the industrial and environmental fields.

\section{Acknowledgement}

The authors would like to acknowledge the Lebanese council for scientific research (CNRSL) for their financial support.

\section{References}

1. R. Abou Naccoul, Université Claude Bernard Lyon 1, 2011

2. C.J. Alcorn, R.J. Simpson, I.E. Leahy, T.J. Peters, Biochem Pharmacol. 45 (1993)

3. P. Dohanyosova, V. Dohnal, D. Fenclova, Fluid Phase Equilibria 214 (2003)

4. W.W. Davis, M.E. Krahl, H.A. Clowes, J. Am. Chem. Soc. 64108 (1942)

5. J. Eisenbrand, K. Baumann, Zeitschrift Für Lebensmittel Untersuchung Und Forschung. 144312 (1970)

6. H.B. Klevens, J. Phys. Colloid Chem. 54283 (1950)

7. W.E. May, S.P. Wasik, D.H. Freeman, Anal. Chem. 50997 (1978)

8. M.M. Miller, S.P. Wasik, G.L. Huang, W.Y. Shiu, D. Makay, Environ. Sci. Technol. 19 (1985)

9. D. Makay and W.Y. Shiu, J. Chem. Eng. Data. 22398 (1977)

10. J. Reza, A. Trejo, L.E. Vera-Avila, Chemosphere 47 933 (2002)

11. F.P. Schwarz, S.P. Wasik, Anal. Chem. 48524 (1976)

12.D.G. Shaw, IUPAC Solubility Data series. In: Hydrocarbons (C8-C36) with Water and Seawater, P. Editor (Ed.). Oxford, England, 1989

13. J. Saab, N. Ouaini, R. Abounaccoul, I. Mokbel, J. Stephan, J. Jose, Fluid Phase Equilibria 264156 (2008)

14. J. Saab, R. Abounaccoul, J. Stephan, C. Goutaudier, R. Ouaini, I. Mokbel, N. Ouaini, J. Jose, Air water soil pollution 209241 (201) 